\title{
Response of fermentation and sulfate reduction to experimental temperature changes in temperate and Arctic marine sediments
}

\author{
Niko Finke ${ }^{1}$ and Bo Barker Jørgensen \\ Department of Biogeochemistry, Max Planck Institute for Marine Microbiology, Bremen, Germany
}

\begin{abstract}
Anaerobic degradation of organic material generally proceeds through a sequence of steps, including polymer hydrolysis, fermentation and respiration or methanogenesis. The intermediates, such as volatile fatty acids (VFA) or $\mathrm{H}_{2}$, are generally maintained at low concentration, showing a close coupling of the terminal oxidation to fermentation. We exposed marine sediments to extreme temperature perturbations to study the nature and robustness of this coupling. Bacterial sulfate reduction and its dependence on fermentation were studied experimentally over a broad temperature range of -0.3 to $40{ }^{\circ} \mathrm{C}$ in sediments from temperate and permanently cold environments. In an Arctic sediment from Svalbard, the apparent optimum temperature for sulfate reduction decreased with prolonged incubation, whereas sulfate reduction rates increased. In a temperate sediment from the North Sea, the apparent optimum temperature was higher and did not change with incubation time. Up to a critical temperature, the concentrations of VFA remained low, $<3 \mu \mathrm{M}$ for acetate and $<1 \mu \mathrm{M}$ for the other VFA, the $\mathrm{H}_{2}$ concentration showed thermodynamic control by sulfate-reducing bacteria, revealing a close coupling of fermentation and sulfate reduction. Above the critical temperature, the concentrations of VFA and $\mathrm{H}_{2}$ increased transiently by 100-1000fold. According to the different in situ temperatures of the samples, the critical temperature was lower for sediments from the Arctic than from the North Sea. The $\mathrm{H}_{2}$ concentrations decreased again upon prolonged incubation to values typical for sulfate-depleted methanogenic sediments. This suggests that fermentative bacteria and methanogenic archaea in both sediments tolerated higher temperatures than the sulfate-reducing community.
\end{abstract}

The ISME Journal (2008) 2, 815-829; doi:10.1038/ismej.2008.20; published online 28 February 2008

Subject Category: microbial population and community ecology

Keywords: hydrogen; marine sediments; sulfate reduction; temperature response; volatile fatty acids

\section{Introduction}

The quality and quantity of organic matter control its rate of degradation in marine sediments (Arnosti et al., 1998; Thamdrup and Fleischer, 1998). Temperature is also a major regulating factor (Westrich and Berner, 1988; Westermann, 1992; Nedwell, 1999; Pomeroy and Wiebe, 2001), as seen by the fact that microbial processes in environments with strong seasonal temperature variation decrease substantially during winter (for example, Crill and Martens, 1987; Jørgensen and Sørensen, 1985; Westrich and Berner, 1988). Yet, sediments from

Correspondence: N Finke, Department of Biogeochemistry, Max Planck Institute for Marine Microbiology, Celsiusstr. 1, Bremen 28359, Germany.

E-mail: nfinke@web.de

${ }^{1}$ Current address: Exobiology Branch, NASA Ames Research Center, Mailstop 239-4, Moffett Field, CA 94035, USA

Received 22 November 2007; revised 21 January 2008; accepted 21 January 2008; published online 28 February 2008 permanently cold sites may have process rates, for example, of sulfate reduction or nitrification, similar to rates at warmer temperate sites (Sagemann et al., 1998; Thamdrup and Fleischer, 1998; Knoblauch and Jørgensen, 1999).

The response of microbial processes to short-term changes in temperature appears to depend on the in situ temperature (Arnosti et al., 1998; Sagemann et al., 1998) and on the specific metabolic process (Arnosti et al., 1998; Arnosti and Jørgensen, 2003). Bacteria show a wide range of temperature adaptations (Wiebe et al., 1993; Isaksen and Jørgensen, 1996; Knoblauch and Jørgensen, 1999; Nedwell, 1999). Sulfate reduction rates (SRRs), accordingly, show a dependence on incubation temperature, which is related to the in situ temperature of the sediment (Arnosti et al., 1998; Sagemann et al., 1998). Carbohydrate hydrolysis was found to have a different temperature response than SRR, with a similar optimum temperature but a higher maximum temperature in permanently cold and 
temperate environments (Arnosti et al., 1998). Acetate production from organic matter in coastal sediment (Wellsbury et al., 1997) showed a higher temperature optimum and maximum than sulfate reduction from comparable temperate sites (Arnosti et al., 1998), both in short-term incubations. Long-term incubations showed a slight transient accumulation of acetate at $30^{\circ} \mathrm{C}$ but no increased concentrations of $\mathrm{H}_{2}$ or acetate between 0 and $50{ }^{\circ} \mathrm{C}$ after 18 months of incubation (Parkes et al., 2007). Interestingly, thermophilic sulfate-reducing prokaryotes have been found in temperate (Isaksen et al., 1994) and permanently cold sediments (Nickel, 2006; C Hubert, unpublished data). The source of these bacteria, which are inactive at the low in situ temperatures, is unknown to date.

In anoxic ecosystems, organic matter is degraded through a sequence of steps with different microorganisms involved (for example, Capone and Kiene, 1988). The first step is an extracellular hydrolytic degradation of polymers followed by a fermentation of the monomers or oligomers to mainly volatile fatty acids (VFAs) and $\mathrm{H}_{2}$. Finally, when an electron acceptor is available, a terminal oxidation of the VFA and $\mathrm{H}_{2}$ to $\mathrm{CO}_{2}$ and water occurs. In marine shelf sediments, sulfate reduction is the most important anaerobic terminal oxidation step (Jørgensen, 1982). Under in situ conditions, sulfate reduction and fermentation are usually well balanced as evidenced by low concentrations of the intermediates, VFA and $\mathrm{H}_{2}$. Under steady state conditions, $\mathrm{H}_{2}$ concentrations are kept at a minimum, controlled by a thermodynamic change in free energy of -15 to $-20 \mathrm{~kJ} \mathrm{~mol}^{-1}$ for its oxidation with the respective electron acceptor (Lovley and Goodwin, 1988; Schink, 1997; Hoehler et al., 1998). The VFA concentrations do not appear to be thermodynamically controlled but usually remain in the lower micromolar range (for example, Christensen and Blackburn, 1982; Wu and Scranton, 1994; Wellsbury and Parkes, 1995). The actual mechanisms controlling VFA concentrations in marine pore waters are not yet understood. Changes of the sediment structure or biogeochemistry can, however, influence the balance between fermentation and the terminal oxidation, leading to higher concentrations of the fermentation products. Hoehler et al. (1998) reported transiently increased VFA and $\mathrm{H}_{2}$ concentrations in Cape Lookout Bight sediments during the transition from sulfate-reducing to methanogenic metabolism. Mixing of marine sediments also disturbs the close coupling between fermentation and sulfate reduction causing the VFA and $\mathrm{H}_{2}$ concentrations to increase (Finke, 1999; Arnosti et al., 2005). The response of the VFA concentrations to mixing was enhanced by increased temperature, but the steady state concentrations after 8 days of incubation were the same, regardless of the incubation temperature (Finke, 1999).
This transient uncoupling between sulfate reduction and fermentation by a temperature increase is not well understood. Under steady state conditions, the sulfate-reducing prokaryotes are generally electron donor limited and, thus, depend on the activity of the fermenting microorganisms to increase their metabolism. As a result of such a limitation, the addition of substrate to a hydrothermal sediment from the Guayamas Basin resulted in a decrease of the apparent optimum temperature for sulfate reduction in the sediment (Elsgaard et al., 1994). The authors concluded that the sulfate reducers were substrate limited at their optimum temperature and that the fermenting microorganisms had a higher optimum temperature. It is generally not clear whether short- and long-term responses of sulfate reducers are the same and whether sulfate reducers and the fermenters respond similarly to temperature changes. A faster response of the fermenters following an upshift in temperature would lead to a transient increase in fermentation products. A potentially faster response of the sulfate reducers would be masked by the substrate limitation and would, therefore, not lead to a change in substrate concentration or SRR.

Studies of temperate sediments during different seasons showed similar temperature response of sulfate reduction during summer and winter (Jørgensen, unpublished data), whereas aerobic respiration showed different responses (Thamdrup et al., 1998). This indicates that aerobic populations adapted to different temperatures alternate over the course of the year, rather than one population persisting, that is well adapted to the whole seasonal temperature range. In the absence of seasonal temperature changes in permanently cold environments, it would be plausible that one specialized population persists throughout the year.

In the present study, we investigated the influence of a sudden temperature shift on SRR and VFA and $\mathrm{H}_{2}$ concentrations in sediments from permanently cold and from temperate environments. A goal of our temperature experiments was to understand how robust the coupling between fermentation and anaerobic respiration is during perturbations of this key environmental factor and how this may depend on the natural variations.

\section{Materials and methods}

Sampling sites

Sediments were sampled at four different sites. The Stations BC and J are located in deep and permanently cold Arctic fjords on the west coast of Svalbard, whereas the Stations Neuharlinger Siel (NHS) and Weddewarden (WW) are situated on mud flats in the German Wadden Sea. 


\section{Svalbard}

Station BC is located at $78^{\circ} 31^{\prime} \mathrm{N}, 015^{\circ} 06^{\prime} \mathrm{E}$ in the Nordfjorden. Sediments were taken with a haps corer (Kanneworff and Nicolaisen, 1983) in September 2001. The bottom water temperature was $1{ }^{\circ} \mathrm{C}$ and the water depth was $100 \mathrm{~m}$. Sediment from the 3-8 cm depth horizon was transferred into brown glass jars, capped without air space and stored at $0{ }^{\circ} \mathrm{C}$. Station J is located at $79^{\circ} 93^{\prime} \mathrm{N}, 11^{\circ} 05^{\prime} \mathrm{E}$ in the Smeerenburgfjorden. Samples were taken with a haps corer in July 1999. The bottom water temperature was $0{ }^{\circ} \mathrm{C}$ and the water depth was $215 \mathrm{~m}$. Sediment from the depth of $2-9 \mathrm{~cm}$ was transferred into brown glass bottles and stored at $0{ }^{\circ} \mathrm{C}$.

Station BC was used for measurements of VFA and $\mathrm{H}_{2}$ over the course of the 29-day incubation. Additionally, sulfate concentrations were measured after 10 days to calculate SRRs. Station J was used for radiotracer studies of SRRs.

\section{Wadden Sea}

Station NHS is located at Neuharlinger Siel at $53^{\circ} 42^{\prime} 8.5^{\prime \prime} \mathrm{N}, 7^{\circ} 42^{\prime} 33.2^{\prime \prime} \mathrm{E}$ on an intertidal mud flat about $15 \mathrm{~m}$ seawards from the shore break in the German Wadden Sea. The samples were taken by hand in October 2001 during low tide and sediment from the depth of $5-12 \mathrm{~cm}$ was filled into brown glass jars and stored at $16{ }^{\circ} \mathrm{C}$. At the time of sampling, the in situ temperature ranged from $16{ }^{\circ} \mathrm{C}$ at the sediment surface to $10.5^{\circ} \mathrm{C}$ at a depth of $15 \mathrm{~cm}$. During the course of the year, the sediment surface temperature ranges from $-1{ }^{\circ} \mathrm{C}$ to about $30{ }^{\circ} \mathrm{C}$. Station WW is located at Weddewarden at $53^{\circ} 36.1^{\prime} \mathrm{N}, 8^{\circ} 31.3^{\prime} \mathrm{E}$ on an intertidal mud flat on the east coast of the estuary of the German river Weser. Sediments were collected by hand in June 1995. The sediment temperature was $20^{\circ} \mathrm{C}$ at the sediment surface. The annual temperature ranges similarly from 0 to $30^{\circ} \mathrm{C}$. Samples were collected at low tide by hand and transported directly to the laboratory.

Station NHS was used for measurements of VFA and $\mathrm{H}_{2}$ over the course of the 9-day incubation. Additionally, sulfate concentrations were measured after 6 days to calculate SRRs. Station WW was used for radiotracer studies of SRRs.

\section{Incubation}

At every timestep and temperature, a single sample was taken for every parameter determined. Replication was obtained through neighboring samples taken at slightly different temperatures and repeated sampling at different time points. In a few cases, individual extreme data points were excluded from the regression lines. Three different incubation phases were used for the experiment. The time between the sediment mixing and placement into the temperature gradient block is referred to as the preincubation, the time in the gradient block as incubation and the time during which radiolabelled sulfate was present in the samples as tracer incubation.

The sediments from Stations J and WW were homogenized and diluted 1:1 with oxygen-free seawater from the sampling site. To ensure that the observed SRRs were controlled by the different incubation temperatures and not by changing fermentation rates at the different temperatures and thus different availability of VFA, a mixture of acetate, butyrate, formate, lactate and propionate final concentration $1 \mathrm{mM}$ was added to the slurry. Previous incubations with sediment from Svalbard showed no difference in the short-term optimum temperature for sediment with and without substrate addition (data not shown). Subsamples of 8-10 $\mathrm{ml}$ were transferred into $\mathrm{N}_{2}$-flushed glass tubes, which were immediately sealed with butyl rubber stoppers. The tubes were incubated for $1 \mathrm{~h}$ (Station WW) or for $0.3,2.1,4.2,6.2,8.5,10.8$ and 11.5 days (Station J) in a temperature gradient block (Sagemann et al., 1998), prior to the addition of $100 \mu \mathrm{l}$ of ${ }^{35} \mathrm{SO}_{4}^{2-}$-tracer solution $(100 \mathrm{kBq}$, carrierfree, specific activity $37 \mathrm{GBq} \mathrm{mol}^{-1}$, Amersham, Buckinghamshire, UK). The temperature range in the gradient block was set at -3.5 to $40{ }^{\circ} \mathrm{C}$. At each sampling time, one row of tubes covering the temperature spectrum in the gradient block was injected and sampled for SRRs. The tracer incubation was terminated by addition of $1 \mathrm{ml}$ of $20 \%$ zinc acetate solution and freezing of the sample. Reduced ${ }^{35} \mathrm{~S}$ was analyzed by the single-step chromium reduction method (Fossing and Jørgensen, 1989), and the SRRs were calculated per cubic centimeters of undiluted sediment as described by Jørgensen (1978).

The sediment from Stations BC and NHS was filled into gas-tight plastic bags (Hansen et al., 2000), homogenized without airspace and preincubated for 3 weeks at $0{ }^{\circ} \mathrm{C}$ for Station BC and at $16{ }^{\circ} \mathrm{C}$ for Station NHS. This preincubation was necessary to allow the VFA and $\mathrm{H}_{2}$ to decrease to in situ levels after a transient increase, seen in previous studies (Finke, 1999; Arnosti et al., 2005; Finke et al., 2007a, b). About $5 \mathrm{ml}$ of the sediment was filled into $\mathrm{N}_{2}$-flushed glass tubes. The tubes were sealed with thick butyl rubber stoppers and placed in a temperature gradient block with a temperature range of $0.3-40{ }^{\circ} \mathrm{C}$. The tubes were placed in three rows of parallel holes in the block at temperature increments of $\sim 1.3{ }^{\circ} \mathrm{C}$. Pre-experiments were run to determine the appropriate time course of the experiment. The time points for VFA sampling were chosen at maximum, decreasing and finally low $\mathrm{H}_{2}$ concentrations at the highest temperatures. High temperatures were chosen as these proved to be the most dynamic in terms of $\mathrm{H}_{2}$ and VFA concentrations over the course of the experiment.

The concentrations of $\mathrm{H}_{2}$ and VFA are discussed for a temperature range above and below a critical temperature $\left(T_{\text {crit }}\right)$. This $T_{\text {crit }}$ is defined as the highest temperature with no significant concentration 
increase compared to samples at lower temperatures. For $\mathrm{H}_{2}$, this means no stronger increase than the thermodynamic control of the concentrations suggests.

\section{$\mathrm{H}_{2}$ measurements}

Hydrogen concentrations in the sediment were determined several times during incubation by a headspace equilibration technique (Lovley and Goodwin, 1988; Hoehler et al., 1998). The $\mathrm{H}_{2}$ concentration in the gas phase was measured with a reduced gas analyzer (RGA3, Trace Analytical). $\mathrm{H}_{2}$ concentrations were calculated from the $\mathrm{H}_{2}$ solubility in seawater (Croizer and Yamamoto, 1974). The concentrations were measured after 1, 2, 4, 6, 10 and 29 days of incubation for the permanently cold Station, BC, and after 2, 3, 4 and 5 days for the temperate Station, NHS. The graph of the 8-day incubation from the pre-experiment is also included.

For temperatures below $25^{\circ} \mathrm{C}$ for Station BC and $30^{\circ} \mathrm{C}$ for Station NHS, the average of two neighboring temperatures was taken to reduce the number of data points and increase the clarity of the graphs.

\section{VFA measurements}

Volatile fatty acids were measured by high-performance liquid chromatography according to Albert and Martens (1997). After 4, 10 and 29 days for the BC samples, and 3, 6 and 9 days for the NHS samples one of the three parallel rows of tubes was centrifuged at $2000 \mathrm{~g}$ at $4{ }^{\circ} \mathrm{C}$ for $10 \mathrm{~min}$. The supernatant was frozen in precombusted brown borosilicate vials. The acids were derivatized with $p$-nitrophenyl hydrazine, separated on high-performance liquid chromatography using a LiChrosphere 80/100 (Knauer, Berlin, Germany) column and the concentrations determined from the absorption on a UV/VIS detector (Linear) at $400 \mathrm{~nm}$. The detection limits for the different acids were $0.5 \mu \mathrm{M}$ for glycolate, lactate and propionate; $1 \mu \mathrm{M}$ for acetate, formate and isobutyrate; $2 \mu \mathrm{M}$ for butyrate and $5 \mu \mathrm{M}$ for isovalerate and valerate. Formate could be measured only at relatively low acetate levels, as the two peaks had similar retention times.

\section{Sulfate measurements}

A $50 \mu \mathrm{l}$ subsample was taken from the pore water and added to $50 \mu \mathrm{l} 20 \%$ Zinc acetate to precipitate sulfide. The samples were frozen until analysis. The sulfate concentration was measured using non-suppressed ion chromatography with a Waters IC-Pak anion exchange column $(50 \times 4.6 \mathrm{~mm})$ and a Waters 430 conductivity detector (Ferdelman et al., 1997). The eluant was $1 \mathrm{~mm}$ isophthalate buffer in $10 \%$ methanol, adjusted to $\mathrm{pH} 4.5$ with saturated sodium borohydrate.

\section{Calculated $\mathrm{H}_{2}$ concentrations}

In aquatic systems, under steady-state conditions, $\mathrm{H}_{2}$-consuming bacteria bring down the $\mathrm{H}_{2}$ concentration to a level where they gain only about 10$20 \mathrm{~kJ} \mathrm{~mol}^{-1}$ from the $\mathrm{H}_{2}$ oxidation (Lovley and Goodwin, 1988; Schink, 1997; Hoehler et al., 1998). Steady-state $\mathrm{H}_{2}$ concentrations were calculated for the different $\mathrm{H}_{2}$ oxidation pathways: sulfate reduction, acetogenesis and methanogenesis (Damgaard and Hanselmann, 2002). The calculations are based on the equation:

$$
\Delta G_{\mathrm{r}}=\Delta G^{\circ}+R T * \ln \left(\frac{\Pi P^{y}}{\Pi E^{z}}\right)
$$

where $\Delta G_{\mathrm{r}}$ is the Gibbs free energy for the reaction under the actual conditions of reaction, $\Delta G^{\circ}$ is the standard Gibbs free energy, $\mathrm{R}$ is the gas constant, $T$ the temperature in Kelvin. $\Pi P^{y}$ and $\Pi E^{z}$ are the mathematical products of the activities of reaction products and educts, respectively, each raised to its stoichiometric coefficient $y$ and $z$, respectively.

The free energy was calculated for different temperatures according to:

$$
\Delta G_{\mathrm{r}}(T)=T *\left(\frac{\Delta G_{\mathrm{r}}}{298 \mathrm{~K}}+\left(\frac{\Delta H^{\circ}}{T}-\frac{\Delta H^{\circ}}{298 \mathrm{~K}}\right)\right)
$$

where $\Delta H^{\circ}$ is the enthalpy of the reaction. Temperature changes of the enthalpy were not included in the calculation as they were relatively small within the tested temperature range. Rearrangement of Equation (1) gives the equation for calculation of the $\mathrm{H}_{2}$ concentration at steady-state conditions. For sulfate reduction:

$$
\begin{aligned}
& {\left[\mathrm{H}_{2}\right](T)} \\
& \quad=\left(\frac{\left[\mathrm{HS}^{-}\right] *\left[\mathrm{OH}^{-}\right]}{\left[\mathrm{SO}_{4}^{2-}\right]} * \exp \left(\frac{\Delta G_{\mathrm{s}}(T)-\Delta G_{\mathrm{s}}^{\circ}}{R T}\right)\right)^{0.25}
\end{aligned}
$$

for methanogenesis:

$$
\begin{aligned}
& {\left[\mathrm{H}_{2}\right](T)} \\
& \quad=\left(\frac{\left[\mathrm{CH}_{4}\right] *\left[\mathrm{OH}^{-}\right]}{\left[\mathrm{HCO}_{3}^{-}\right]} * \exp \left(\frac{\Delta G_{\mathrm{m}}(T)-\Delta G_{\mathrm{m}}^{\circ}}{R T}\right)\right)^{0.25}
\end{aligned}
$$

and for acetogenesis:

$$
\begin{aligned}
& {\left[\mathrm{H}_{2}\right](T)} \\
& \quad=\left(\frac{[\text { acetate }] *\left[\mathrm{OH}^{-}\right]}{\left[\mathrm{HCO}_{3}^{-}\right]^{2}} * \exp \left(\frac{\Delta G_{\mathrm{a}}(T)-\Delta G_{\mathrm{a}}^{\circ}}{R T}\right)\right)^{0.25}
\end{aligned}
$$

$\Delta G_{\mathrm{s}}^{\circ}(T), \Delta G_{\mathrm{m}}^{\circ}(T)$ and $\Delta G_{\mathrm{a}}^{\circ}(T)$ are the temperatureadjusted free energies for sulfate reduction, methanogenesis and acetogenesis, respectively. 
The equilibrium $\mathrm{H}_{2}$ concentrations for control by sulfate reducers were calculated according to:

$$
4 \mathrm{H}_{2}+\mathrm{SO}_{4}^{2-} \rightarrow \mathrm{HS}^{-}+3 \mathrm{H}_{2} \mathrm{O}+\mathrm{OH}^{-}
$$

The basis for the calculations is a free energy of $\Delta G_{\mathrm{s}}=-20$ and $-35 \mathrm{~kJ} \mathrm{~mol}^{-1}$ for the Stations NHS and BC, respectively (see discussion). The hydrogen sulfide concentration was set at $1 \mu \mathrm{M}$, and sulfate concentrations according to a regression line through the sulfate concentrations shown in Figures 1a and 2a. The sulfide was not measured in the incubations but at the time of sediment sampling, concentrations were at or below the detection limit of $1 \mu \mathrm{M}$ for all samples (data not shown).

The equilibrium $\mathrm{H}_{2}$ concentrations for methanogenic control were calculated according to:

$$
4 \mathrm{H}_{2}+\mathrm{HCO}_{3}^{-} \rightarrow \mathrm{CH}_{4}+2 \mathrm{H}_{2} \mathrm{O}+\mathrm{OH}^{-}
$$

assuming a carbonate concentration of $5 \mathrm{mM}$, a methane concentration of $0.1 \mathrm{mM}$ and a $\Delta G_{\text {r }}$ of -20 or $-35 \mathrm{~kJ} \mathrm{~mol}^{-1}$ for methanogenesis (see discussion
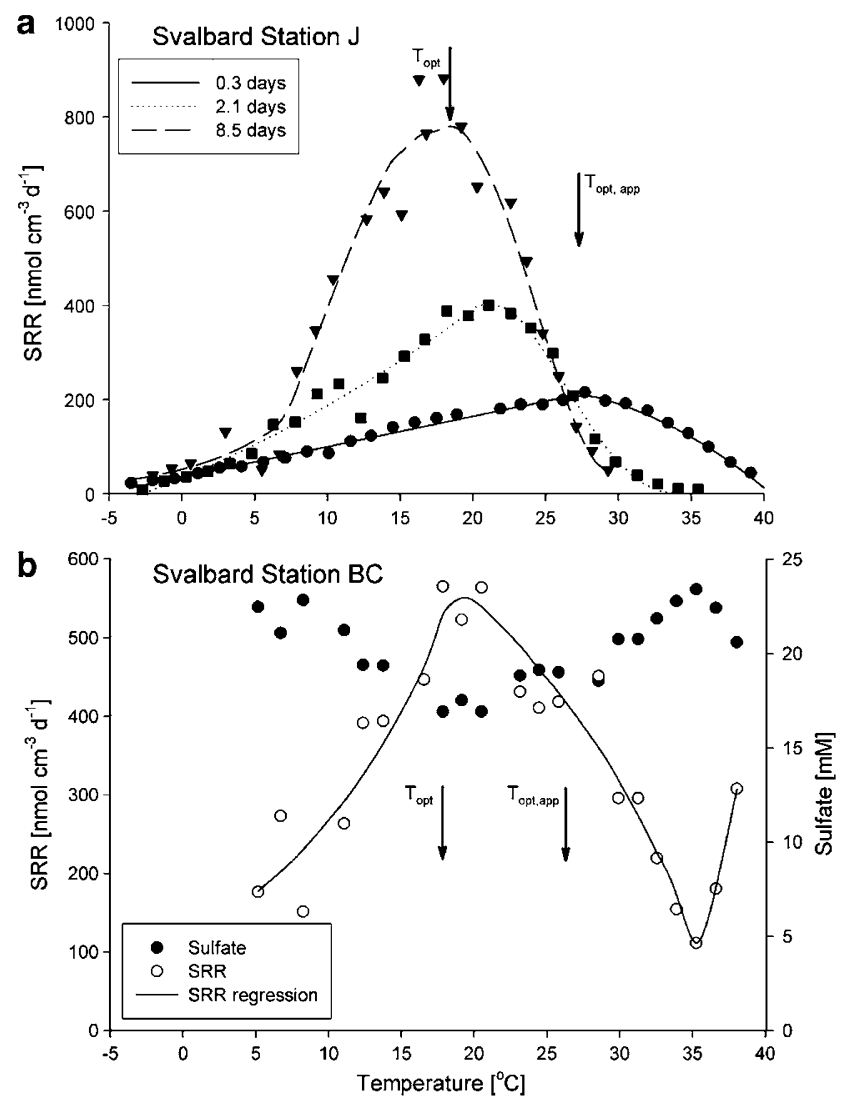

Figure 1 (a) Sulfate reduction rates (SRRs) from the permanently cold Station J, measured after various durations of incubation. A mixture of volatile fatty acids (VFA) at $1 \mathrm{~mm}$ final concentration was added (see Materials and methods for details). (b) Sulfate concentrations and calculated SRR from the permanently cold Station BC, measured after 10 days of incubation. SRRs at Station $\mathrm{BC}$ were calculated from the decrease in sulfate concentration showing the cumulative effect of the sulfate reduction on the sulfate concentration. $T_{\mathrm{opt} \text {, app }}=$ apparent optimum temperature after the short incubation, $T_{\text {opt }}=$ optimum temperature after the long incubation, both as determined with the radiotracer incubation for Station J. section). The $\Delta G_{\mathrm{r}}$ values were chosen to reflect the free energy of hydrogenotrophic sulfate reduction at the upper temperature end. In comparison, methane concentrations in Cape Lookout Bight sediments increased to about $1 \mathrm{~mm}$ within 30 days after sulfate depletion at $22^{\circ} \mathrm{C}$ (Hoehler et al., 1994). Methanogenesis rates in Cape Lookout Bight sediments are about 10-fold higher than typically found in methanogenic Wadden Sea sediments (M Krueger, personal communication). As the investigated sediments do not undergo sulfate depletion on a seasonal basis, the rate of methane increase was, accordingly, assumed to be $1 / 10$ of the rate found in Cape Lookout Bight despite the higher temperature in our incubations. An amount of $5 \mathrm{mM}$ of dissolved inorganic carbon is a typical concentration in these sediments (Böttcher et al., 2000).

The equilibrium $\mathrm{H}_{2}$ concentrations for acetogenic control were calculated according to:

$$
4 \mathrm{H}_{2}+2 \mathrm{HCO}_{3}^{-} \rightarrow \mathrm{CH}_{3} \mathrm{COO}^{-}+3 \mathrm{H}_{2} \mathrm{O}+\mathrm{OH}^{-}
$$
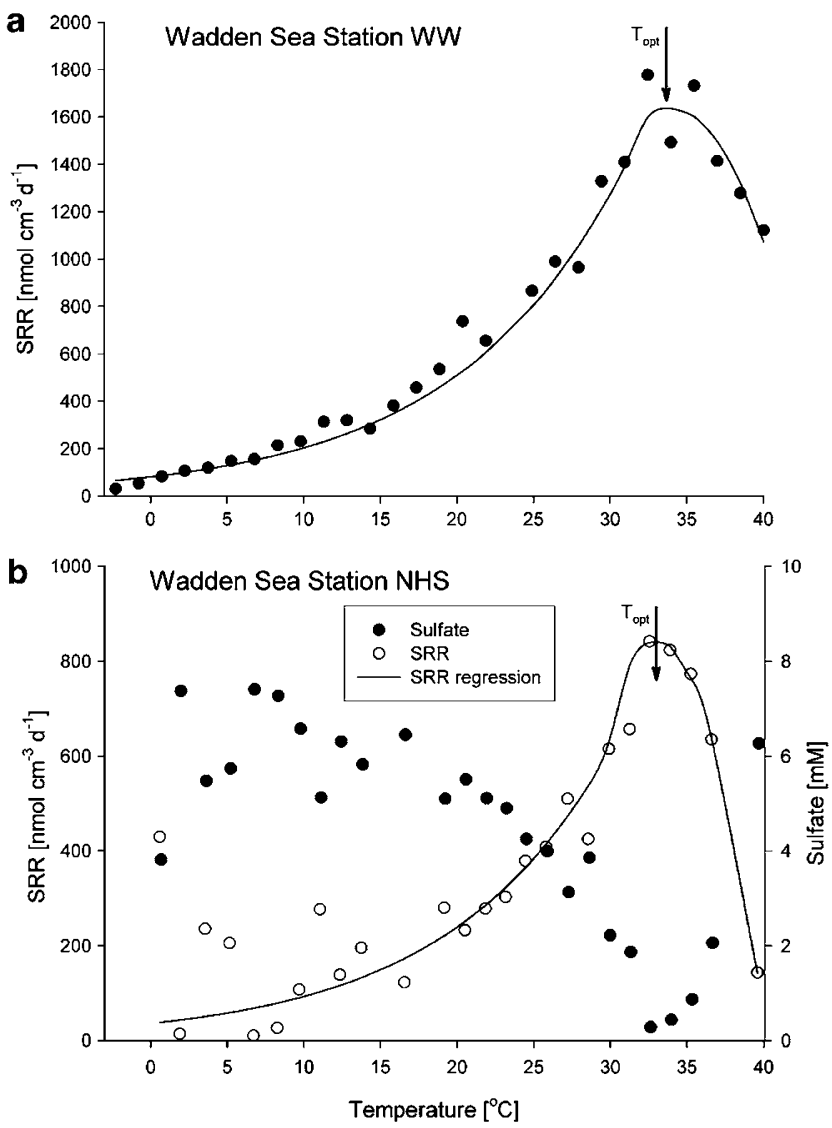

Figure 2 (a) Sulfate reduction rate (SRR) from the temperate Station WW in the German Wadden Sea, after $1 \mathrm{~h}$ of incubation. The data were previously published by Arnosti et al. (1998) and are reprinted with kind permission of the authors. A mixture of volatile fatty acids (VFA) at $1 \mathrm{~mm}$ final concentration was added (see Materials and methods for details). (b) Sulfate concentrations and calculated SRR from the temperate Station NHS in the Wadden Sea, measured after 6 days of incubation. SRRs were calculated from the decrease in sulfate concentration showing the cumulative effect of sulfate reduction on the sulfate concentration. $T_{\text {opt }}=$ optimum temperature for SRR. 
assuming a carbonate concentration of $5 \mathrm{mM}$ and an acetate concentration of $2 \mathrm{mM}$, as found in our incubations at high temperature, and a $\Delta G_{\mathrm{r}}$ of $-35 \mathrm{~kJ} \mathrm{~mol}^{-1}$ for acetogenesis.

\section{Results}

\section{Sulfate reduction}

Svalbard. Sulfate reduction rates in Svalbard Station J sediment following 0.3, 2.1 and 8.5 days of incubation in the temperature gradient block are presented in Figure 1a. After 0.3 days, SRR increased 10-fold with temperature, from $20 \mathrm{nmol} \mathrm{cm}^{-3} \mathrm{day}^{-1}$ at $-3.6{ }^{\circ} \mathrm{C}$ to $200 \mathrm{nmol} \mathrm{cm}^{-3} \mathrm{day}^{-1}$ at $27^{\circ} \mathrm{C}$. At higher temperatures, SRRs decreased again to $40 \mathrm{nmol} \mathrm{cm}^{-3} \mathrm{day}^{-1}$ at $39^{\circ} \mathrm{C}$. After 2.1 days, sulfate reduction increased from $7 \mathrm{nmol} \mathrm{cm}^{-3}$ day $^{-1}$ at $-2.8{ }^{\circ} \mathrm{C}$ to a maximum of $480 \mathrm{nmol} \mathrm{cm}^{-3}$ day $^{-1}$ at $21^{\circ} \mathrm{C}$. The SRRs decreased at higher temperatures to rates less than $9 \mathrm{nmol} \mathrm{cm}^{-3} \mathrm{day}^{-1}$ at $35^{\circ} \mathrm{C}$. After 8.5 days, the highest SRR was $880 \mathrm{nmol} \mathrm{cm}^{-3} \mathrm{day}^{-1}$ and the optimum temperature $\left(T_{\text {opt }}\right)$ had dropped by $9^{\circ} \mathrm{C}$, from the initial 27 to $18{ }^{\circ} \mathrm{C}$. The highest temperature tested for this incubation was $29^{\circ} \mathrm{C}$. The temperature optima after even longer incubations were similar to the 8.5 days data, although with more scatter (data not shown).

Pore water sulfate concentrations were measured in the sediment from Svalbard Station BC after 10 days of incubation (Figure 1b). The sulfate concentrations in the pore water were about $23 \mathrm{mM}$ at the lower temperatures and decreased with increasing temperature to a minimum of $17 \mathrm{mM}$ at $18-20^{\circ} \mathrm{C}$. At temperatures above $20^{\circ} \mathrm{C}$, the concentration increased again, reaching $24 \mathrm{mM}$ at $35^{\circ} \mathrm{C}$, and showed slightly lower values at the maximum temperature tested. SRRs were, in this case, calculated from the decrease in sulfate concentration showing the accumulative effect of sulfate reduction over the whole incubation. The initial sulfate concentration of $25 \mathrm{mM}$ was used for the calculation of SRRs. In contrast to Figure 1a, which shows the SRR measured during a short radiotracer incubation, the results in Figure 1b, thus, show the mean SRRs throughout the entire incubation period. The calculated SRR curve for Station BC shows an optimum at $18-20^{\circ} \mathrm{C}$, similar to Station J.

Wadden Sea. The SRRs in sediment slurries from the temperate tidal flat at Station WW are shown in Figure 2a. The tracer incubations were carried out after an incubation for $1 \mathrm{~h}$ in the temperature gradient block. The rates increased 60 -fold with temperature, from $30 \mathrm{nmol} \mathrm{cm}^{-3} \mathrm{day}^{-1}$ at $-3.5{ }^{\circ} \mathrm{C}$ to a maximum of $1800 \mathrm{nmol} \mathrm{cm}^{-3} \mathrm{day}^{-1}$ at $34^{\circ} \mathrm{C}$. The rates decreased again to $1100 \mathrm{nmol} \mathrm{cm}^{-3}$ day $^{-1}$ at the highest investigated temperature of $40^{\circ} \mathrm{C}$.

In the sediments from the Wadden Sea Station NHS, pore water sulfate concentrations were measured after 6 days of incubation (Figure 2b). The concentrations started at about $6.5 \mathrm{mM}$ at $0.3^{\circ} \mathrm{C}$ and decreased with increasing temperature to reach a minimum of $0.28 \mathrm{mM}$ at $32.5^{\circ} \mathrm{C}$, the $T_{\text {opt }}$. At higher temperatures, the concentration increased again to about $6.5 \mathrm{mM}$ at $40^{\circ} \mathrm{C}$. SRRs were calculated from the decrease in sulfate concentration over time and showed a temperature optimum of $33^{\circ} \mathrm{C}$. The initial sulfate concentration of $7.5 \mathrm{mM}$ was used for the calculation.

\section{$\mathrm{H}_{2}$}

Svalbard. Hydrogen concentrations in the tubes with sediment from Svalbard Station BC were measured at six different time points: after 1, 2, 4, 6,10 and 29 days of incubation in the temperature gradient block (Figure 3). $\mathrm{H}_{2}$ concentrations are plotted together with a hydrogen equilibrium curve
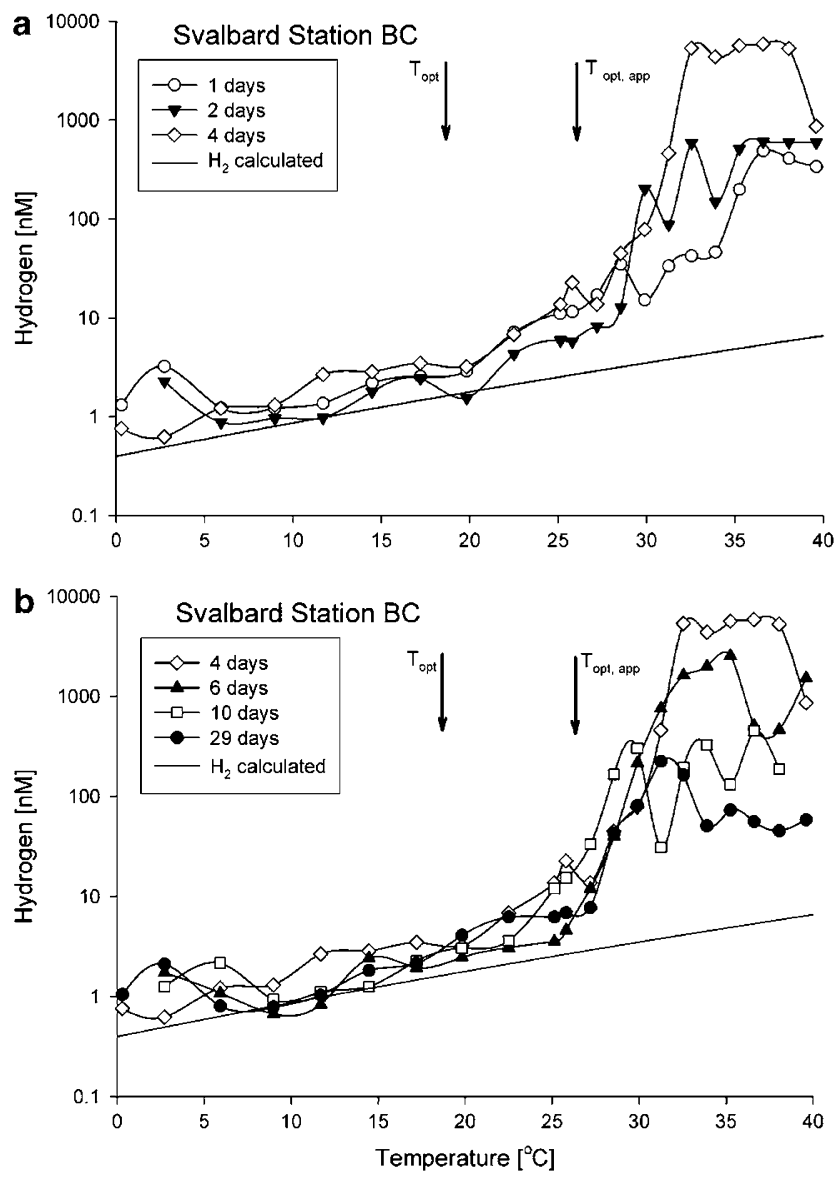

Figure 3 Hydrogen concentrations in the samples from the permanently cold Svalbard Station BC measured after different incubation periods: (a) 1-4 days incubation, (b) 4-29 days incubation. $T_{\mathrm{opt} \text { app }}=$ apparent optimum temperature after the short term incubation for sulfate reduction rate (SRR), $T_{\mathrm{opt}}=$ longincubation optimum temperature for SRR, both determined in the radiotracer incubations at Station J (Figure 1a); the solid line shows $\mathrm{H}_{2}$ calculated based on thermodynamic control of $\mathrm{H}_{2}$ oxidation by sulfate; the 4-day incubation data are shown in both figures to help comparison of the changes with time; notice the logarithmic scale for hydrogen. 
based on thermodynamic considerations for sulfatereducing conditions (Hoehler et al., 1998).

The $\mathrm{H}_{2}$ concentrations fall on a theoretical curve based on an energy yield of $-35 \mathrm{~kJ} \mathrm{~mol}^{-1} \mathrm{~K}^{-1}$ for sulfate reduction over a broad temperature range. Concentrations began to deviate from that curve above a critical temperature $\left(T_{\text {crit }}\right)$. This $T_{\text {crit }}$ decreased from $34{ }^{\circ} \mathrm{C}$ after 1 day of incubation to $25^{\circ} \mathrm{C}$ after 4 days and later. After 1 day, the concentration of $\mathrm{H}_{2}$ reached a maximum concentration of $500 \mathrm{nM}$ at $36{ }^{\circ} \mathrm{C}$. After two days, the maximum concentration had increased to $600 \mathrm{nM}$ at $36^{\circ} \mathrm{C}$. With prolonged incubation, the maximum $\mathrm{H}_{2}$ concentrations increased to a maximum of $5800 \mathrm{nM}$ at a temperature of $36^{\circ} \mathrm{C}$ after 4 days. After even longer incubation, however, the peak in $\mathrm{H}_{2}$ concentration began to decrease again and was only $220 \mathrm{nM}$ at $30^{\circ} \mathrm{C}$ after 29 days of incubation (Figure $3 b$ ).

Wadden Sea. Hydrogen concentrations in sediment from Wadden Sea Station NHS, the temperate tidal flat, were measured at five different time points: after 2, 3, 4, 5 and 8 (pre-experiment) days of incubation (Figure 4). The $\mathrm{H}_{2}$ concentrations are plotted together with a $\mathrm{H}_{2}$ equilibrium curve based on thermodynamic considerations for sulfate-reducing conditions (Hoehler et al., 1998).

The $\mathrm{H}_{2}$ concentrations are parallel to the theoretical curve based on a free-energy yield of $-20 \mathrm{~kJ} \mathrm{~mol}^{-1}$ up to a critical temperature of $31^{\circ} \mathrm{C}$, above which the concentrations show a transient increase. After 2 and 3 days, maximum $\mathrm{H}_{2}$ concentrations of $45 \mathrm{nM}$ were reached at the highest temperatures tested. These maximum concentrations decreased to approximately $10-15 \mathrm{nM}$ during the following days. The $\mathrm{H}_{2}$ concentrations deviated from the $-20 \mathrm{~kJ} \mathrm{~mol}^{-1}$ curve and also at temperatures

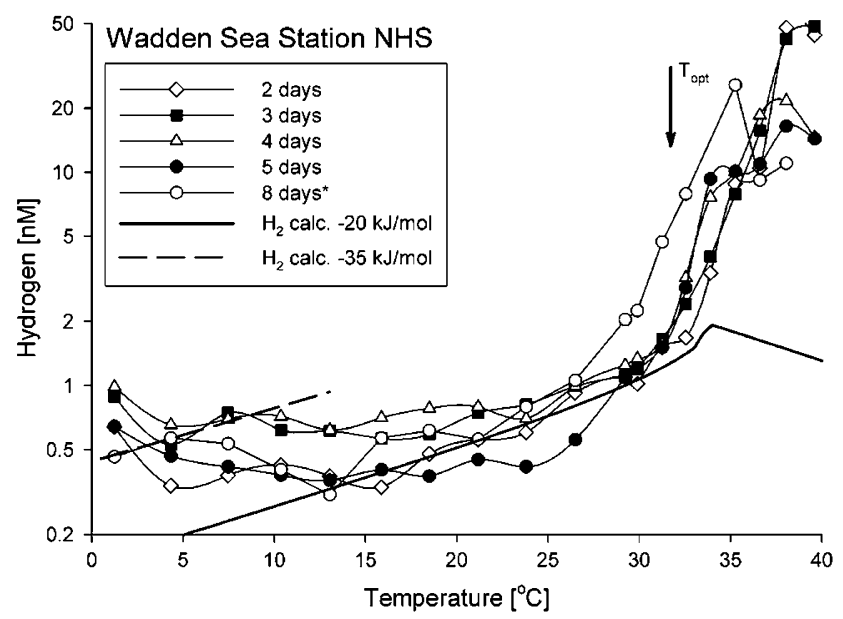

Figure 4 Hydrogen concentrations in sediment from the Wadden Sea Station NHS measured after different incubation periods. $T_{\text {opt }}=$ optimum temperature for sulfate reduction rate (SRR); the solid line shows $\mathrm{H}_{2}$ calculated based on thermodynamic control of $\mathrm{H}_{2}$ oxidation by sulfate reduction; the 8 days incubation from the pre-experiment is included in the graph; notice the logarithmic scale for hydrogen. below $13^{\circ} \mathrm{C}$. The concentrations stayed almost constant around $0.6 \mathrm{nM}$ from $13^{\circ} \mathrm{C}$ down to $0.3^{\circ} \mathrm{C}$, where they reached levels typical for a free-energy yield of $-35 \mathrm{~kJ} \mathrm{~mol}^{-1}$ as found in the sediments from the permanently cold site.

\section{$V F A$}

Svalbard. Volatile fatty acid concentrations in sediment from the permanently cold Station BC were measured at three different time points during the incubations: after 4, 10 and 29 days (Figures 5 and 6). Below the $T_{\text {crit }}\left(25,27\right.$ and $28^{\circ} \mathrm{C}$ at the three different time points, respectively), the concentrations of the fatty acids remained relatively independent of temperature. The only detectable VFAs were acetate and propionate. Above the $T_{\text {crit }}$, the concentrations of acetate, propionate, butyrate, isobutyrate, valerate and isovalerate increased steeply with temperature. Lactate and glycolate concentrations were below or close to the detection limit in all samples at the low temperatures and reached $2-4 \mu \mathrm{M}$ at the highest temperatures, without a clear temperature dependence (data not shown). In all samples, the concentration of acetate was higher than that of the other VFAs. The maximum concentration was $1750 \mu \mathrm{M}$ at $40{ }^{\circ} \mathrm{C}$ (Figure 5). The second most abundant VFA at $40^{\circ} \mathrm{C}$ was propionate $(350 \mu \mathrm{M})$ followed by butyrate $(220 \mu \mathrm{M})$, isobutyrate and isovalerate (both about $140 \mu \mathrm{M}$ ) and valerate $(12 \mu \mathrm{M})$ (Figure 6a). The concentrations of VFA with more than three carbon atoms increased above 27$28^{\circ} \mathrm{C}$, whereas acetate and propionate increased above $25^{\circ} \mathrm{C}$. The concentrations of the acids showed a steady increase with temperature, except for valerate reaching maximum concentration at $34^{\circ} \mathrm{C}$. After 10 days, all VFA concentrations increased above $27^{\circ} \mathrm{C}$, reaching maximum concentrations at

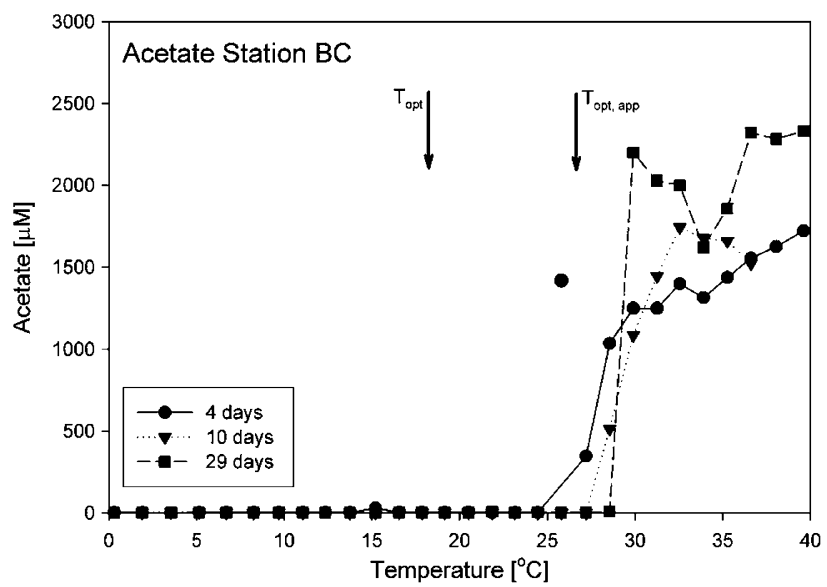

Figure 5 Acetate concentrations in the sediment from the permanently cold Svalbard Station BC after 4, 10 and 29 days of incubation. $T_{\mathrm{opt} \text { app }}=$ apparent optimum temperature after the short incubation for sulfate reduction rate (SRR), $T_{\text {opt }}=$ longincubation optimum temperature for SRR both determined in the radiotracer incubations at Station J (Figure 1a). 

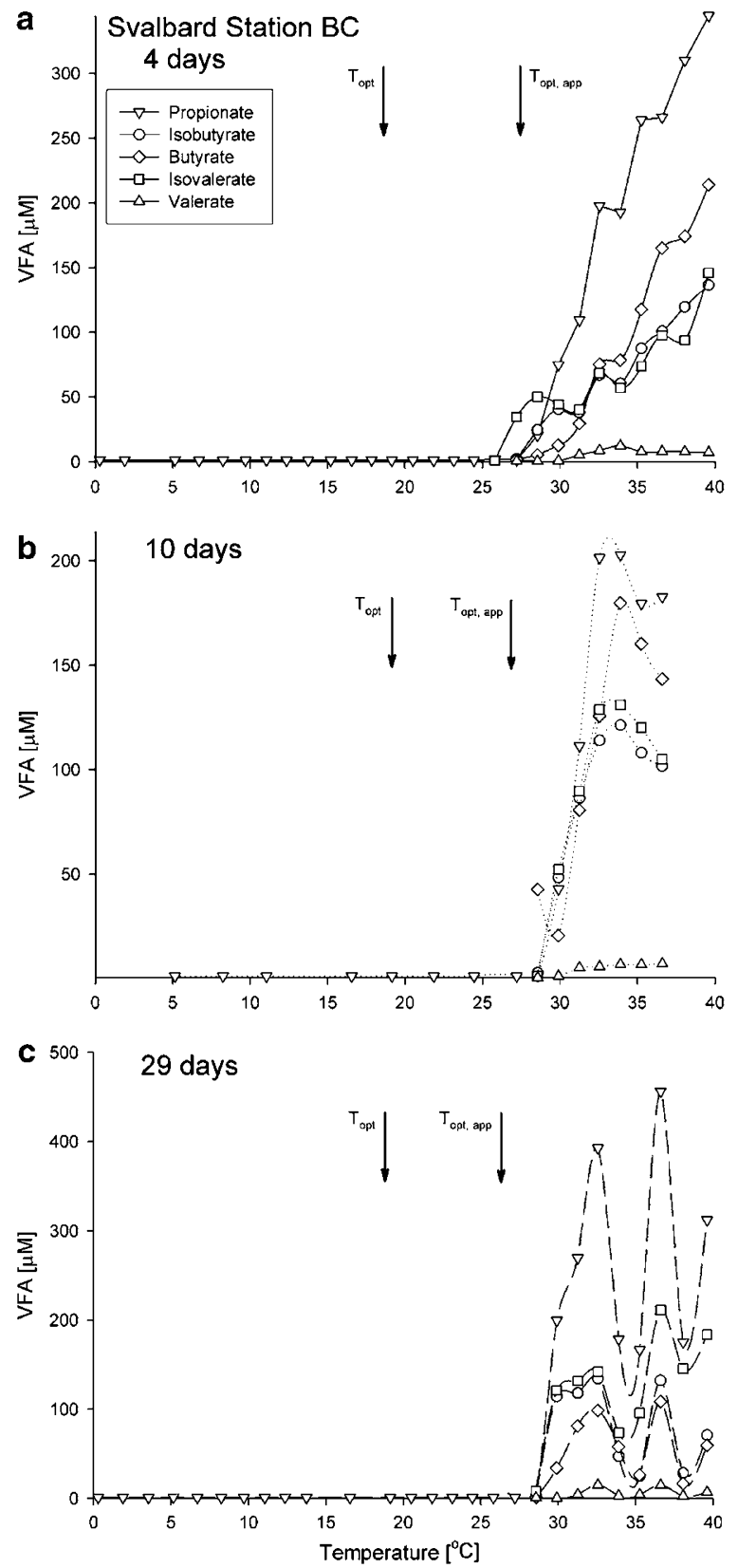

Figure 6 Volatile fatty acid (VFA) concentrations in sediment from the permanently cold Svalbard Station BC after (a) 4, (b) 10 and (c) 29 days of incubation. $T_{\mathrm{opt}, \mathrm{app}}=$ apparent optimum temperature after the short incubation for sulfate reduction rate (SRR), $T_{\text {opt }}=$ long-incubation optimum temperature for SRR both determined in the radiotracer incubations at Station J (Figure 1a).

32-33 ${ }^{\circ} \mathrm{C}$ (Figure 6b). The maximum concentrations were similar to those found after 4 days of incubation.

After 29 days, the concentrations of acetate showed a higher scatter at temperatures above $28{ }^{\circ} \mathrm{C}$ compared to the previous sampling dates (Figure 5). The average acetate concentration was only slightly higher than before. The increase of the VFA concentrations above the $T_{\text {crit }}$ was more abrupt at the third sampling time compared to the previous sampling dates, reaching a plateau with high scatter

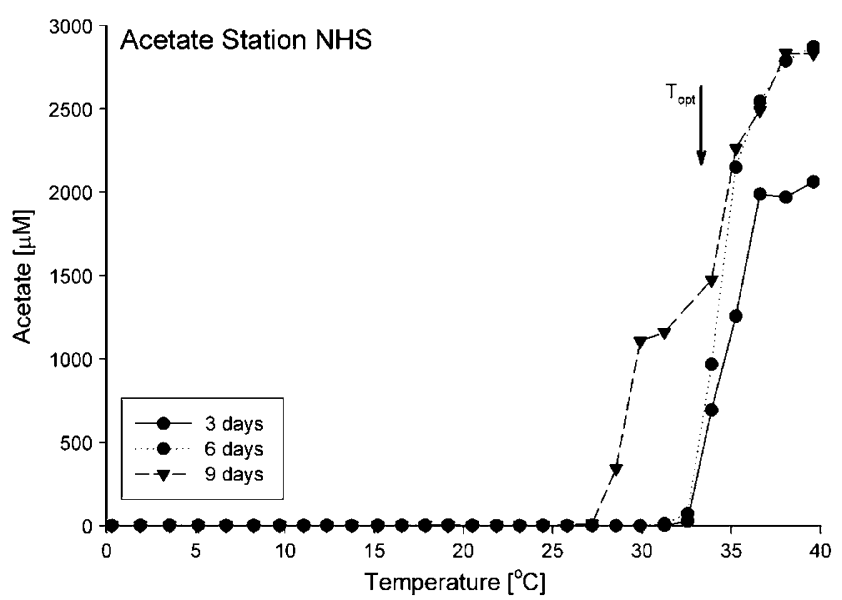

Figure 7 Acetate concentrations in sediment from the temperate Station NHS after 3, 6 and 9 days of incubation. $T_{\text {opt }}=$ optimum temperature for sulfate reduction rate (SRR).

in the concentrations of some VFAs. The highest concentrations were similar to the maximum concentrations of the previous sampling dates.

Wadden Sea. Volatile fatty acid concentrations in the tubes with sediment from the temperate Wadden Sea Station NHS were measured at three different time points along the incubations: after 3,6 and 9 days (Figures 7 and 8 ). The general picture of the temperature response is very similar to the data from the permanently cold site. The concentrations of the acids stayed low and relatively constant at temperatures below the $T_{\text {crit }}$ of 32,32 and $25^{\circ} \mathrm{C}$, respectively, at the three time points. The only detectable VFAs below the $T_{\text {crit }}$ were acetate and propionate. Above the $T_{\text {crit }}$, the concentrations of acetate, propionate, butyrate, isobutyrate, valerate and isovalerate increased. Lactate and glycolate concentrations were below or close to the detection limit in all samples below the $T_{\text {crit }}$ reaching $2-5 \mu \mathrm{M}$ at the highest temperatures (data not shown). The concentration of acetate was the highest in all samples compared to the other VFAs. The steepness of temperature response $\left(\mu \mathrm{M} /{ }^{\circ} \mathrm{C}\right)$ of acetate concentration was always the greatest at the two to three temperatures analyzed just above the $T_{\text {crit }}$, and leveled-off above that. The maximum acetate concentration at the first sampling time was $2000 \mu \mathrm{M}$ at $40{ }^{\circ} \mathrm{C}$ (Figure 7). The second most abundant VFA at $40^{\circ} \mathrm{C}$ was propionate $(660 \mu \mathrm{M})$ followed by butyrate $(250 \mu \mathrm{M})$, isovalerate $(225 \mu \mathrm{M})$, isobutyrate $(200 \mu \mathrm{M})$ and valerate $(10 \mu \mathrm{M})$ (Figure 8a). The $T_{\text {crit }}$ for the VFA with more than three carbon atoms was $34-35^{\circ} \mathrm{C}$, compared to $32{ }^{\circ} \mathrm{C}$ for acetate and propionate. The concentrations of those VFAs showed a steady increase with temperature. After 6 days, the acetate concentrations started to increase at $32{ }^{\circ} \mathrm{C}$ followed by propionate $\left(34^{\circ} \mathrm{C}\right)$, isovalerate, butyrate and isobutyrate $\left(35^{\circ} \mathrm{C}\right)$, and valerate at $\left(37^{\circ} \mathrm{C}\right)$ (Figures 7 and $8 \mathrm{~b}$ ). Compared to the first sampling point, 

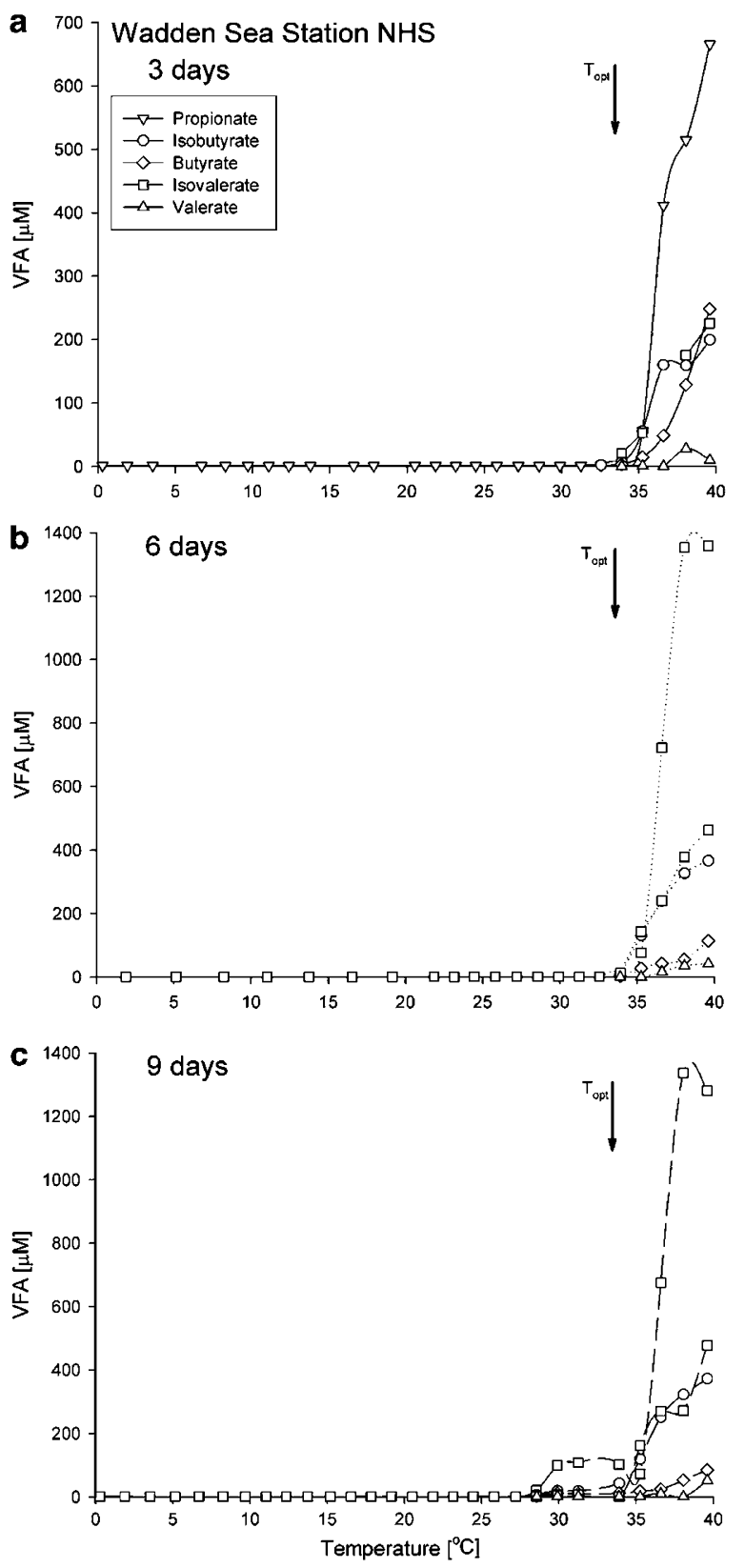

Figure 8 Volatile fatty acid (VFA) concentrations in sediment from the temperate Station NHS after (a) 3, (b) 6 and (c) 9 days of incubation. $T_{\text {opt }}=$ optimum temperature for sulfate reduction rate (SRR).

maximum concentrations were higher for all VFAs, other than butyrate. Acetate reached a maximum concentration of $2900 \mu \mathrm{M}$, followed by propionate $(1350 \mu \mathrm{M})$, isovalerate $(460 \mu \mathrm{M})$, isobutyrate $(370 \mu \mathrm{M})$, butyrate $(115 \mu \mathrm{M})$ and valerate $(42 \mu \mathrm{M})$. After 9 days, the VFAs started to increase already above $27-30{ }^{\circ} \mathrm{C}$ depending on the acid (Figures 7 and 8c). With acetate starting above $27^{\circ} \mathrm{C}$, followed by propionate and then the longer chain acids (besides valerate). Between 33 and $36{ }^{\circ} \mathrm{C}$, the concentrations of all VFAs showed a second major increase with temperature. The maximum concentrations were similar to those found after 6 days of incubation. The VFA increase at temperatures below $30^{\circ} \mathrm{C}$ is almost certainly due to sulfate depletion rather than a temperature effect. This was estimated by extrapolating the sulfate concentrations measured after 6 days to the end of the experiment using the calculated SRRs.

\section{Discussion}

Sulfate reduction

The optimum temperature for SRRs after several days of incubation $\left(T_{\mathrm{opt}}\right)$ from the two permanently cold Stations BC and J were similar (Figure 1). The time series of SRR measured in sediments from Station J showed a downshift of the temperature optimum with increasing incubation time (Figure 1a). After only 0.3 days of incubation, the apparent optimum temperature $\left(T_{\mathrm{opt}, \mathrm{app}}\right)$ of sulfate reduction was $27^{\circ} \mathrm{C}$, similar to the optimum found in a previous investigation with Svalbard sediments using short incubation times (Arnosti et al., 1998; Sagemann et al., 1998). The decrease in the optimum temperatures with prolonged incubation demonstrates that the sulfate reducers could maintain high activity at the highest temperatures only for a limited time, but were not able to keep up this high activity due to thermal stress. At the temperature optimum for the sulfate reducers for longer time periods $\left(T_{\text {opt }}\right)$, the rate increased with prolonged incubation. These findings are consistent with previous results from experiments with sulfatereducing cultures (Knoblauch and Jørgensen, 1999) and from other psychrophilic bacteria (Harder and Veldkamp, 1967; Christian and Wiebe, 1974). Knoblauch and Jørgensen (1999) found higher temperature optima for sulfate reduction than for growth of psychrophilic sulfate reducers in pure cultures. Similar effects are known to occur in methanogens (Miller et al., 1988). Whether the increase in maximum SRR from the $T_{\mathrm{opt} \text { app }}$ to the $T_{\mathrm{opt}}$ is due to growth of sulfate reducers, and thus to a larger population, or whether the increased rates are simply due to higher metabolic activity of the microorganisms. However, previous incubation experiments in the temperate gradient block with Arctic sediments from Svalbard showed no detectable bacterial growth within 10 days in the same temperature range, even after substrate addition (Marc Mussmann, unpublished data).

At station BC, the SRR did not drop as sharply above the $T_{\text {opt }}$ as in incubations with similar length at station J (Figure 1b). The decrease of the sulfate concentration in the pore water at Station BC shows the cumulative effect of sulfate reduction during the whole incubation period, whereas at station J, the measurement comprises just the tracer incubation period. At the $T_{\mathrm{opt}}$, the SRR was high over the entire incubation time resulting in a high-accumulated rate. At the $T_{\mathrm{opt} \text { app }}$, as determined by the tracer 
incubation for Station J after 0.3 days of incubation, sulfate reduction was high only at the beginning and decreased with time. With high rates in the beginning but low rate at the end of the incubation, the cumulative rate, reflected in the sulfate concentration after 10 days, will be intermediate at temperatures between the $T_{\mathrm{opt}}$ and the $T_{\mathrm{opt} \text { app }}$. VFA (Figures 5 and 6) and $\mathrm{H}_{2}$ (Figure 3) concentrations increased above the critical temperature ( $T_{\text {crit }}$ ) for several days, suggesting that the fermenters have a higher maximum temperature compared to the sulfate reducers. At even higher temperatures, the sulfate reduction increases again as indicated by the SRRs at the highest temperatures at station BC. Spore-forming, thermophilic sulfate-reducing bacteria were found in these sediments, which are not active at in situ temperatures (Nickel, 2006; C Hubert, unpublished data).

The optimum temperatures for sulfate reduction at the two temperate Stations, WW and NHS, are almost identical but considerably higher than those found at the permanently cold sites (compare Figures 1 and 2) and are very similar to the highest rates of sulfate reduction below $50{ }^{\circ} \mathrm{C}$ in temperate surface sediment (Parkes et al., 2007). Previous investigations with sediment from a temperate site did not show a strong dependence of the $T_{\text {opt }}$ for SRR on the incubation time (data not shown), as it was found for the permanently cold sediments. Additionally, the SRR curve derived from the sulfate concentrations after 6 days has the same shape as the curve derived from the tracer incubations, indicating that no shift of the temperature optima between short and long incubations occurred. This is in good agreement with studies of mesophilic sulfate reducers in pure culture that have similar temperature optima for growth and sulfate reduction (Isaksen and Jørgensen, 1996) but in contrast to findings for psychophilic bacteria (Harder and Veldkamp, 1967; Christian and Wiebe, 1974; QJ;Knoblauch and Jørgensen, 1999) as well as our incubations of sediment from permanently cold sediments.

The mutually similar temperature-response curves of the two permanently cold stations J and BC from Svalbard differed characteristically from the mutually near-identical temperature response curves of the two temperate tidal flat stations, WW and NHS. Most likely, these results reflect differences between microbial populations in permanently cold versus temperate sediments rather than site-specific features.

\section{Fermentation}

Fermentation in complex environmental settings, such as marine sediments, proceeds via a wide array of different pathways. To date, the overall rate of fermentation cannot be measured directly. The various fermentation steps funnel the hydrolytic breakdown products of sediment organic matter into a relatively small array of intermediates, mainly VFA and $\mathrm{H}_{2}$, which serve as substrates for the terminal oxidizers. By measuring the concentration and the oxidation rates of these products, it is possible to quantify the carbon flow through fermentation.

\section{Intermediates}

Volatile fatty acids and $\mathrm{H}_{2}$ are important intermediates during the degradation of organic matter. VFA and $\mathrm{H}_{2}$ are end products of a range of fermentation reactions and serve as energy source for the terminal oxidizing microorganisms. In aquatic systems, the concentrations are usually very low, indicating that the terminal oxidizing microorganisms (such as sulfate reducers or methanogens) have a larger capacity of oxidizing the fermentation products compared to the fermentation rates. The terminal oxidizers keep the concentrations of VFA and $\mathrm{H}_{2}$ low and are limited by the supply of electron donor from the fermenters. This is particularly obvious in the case of hydrogen. At steady state, $\mathrm{H}_{2}$ concentrations are thermodynamically controlled by the terminal electron accepting process (Lovley and Goodwin, 1988; Hoehler et al., 1998). The terminal oxidizers reduce the concentration to a level at which they gain only $15-20 \mathrm{~kJ} \mathrm{~mol}^{-1}$ (Hoehler, 2004). By lowering the $\mathrm{H}_{2}$ concentration to this level, the terminal oxidizers outcompete other microorganisms using energetically less favorable oxidation reactions, for example, sulfate reduction versus methanogenesis (Hoehler et al., 1998). VFAs apparently do not show a thermodynamic control, but concentrations are usually in the lower micromolar range (for example, Christensen and Blackburn, 1982; Wu and Scranton, 1994; Wellsbury and Parkes, 1995).

In our experiments, VFA and $\mathrm{H}_{2}$ concentrations show two distinct temperature ranges of balance between production and consumption. Below a critical temperature $\left(T_{\text {crit }}\right)$, which is close to the $T_{\text {opt,app }}$ and the $T_{\text {opt }}$ for sulfate reduction of the permanently cold and temperate sediments, respectively, the concentrations remain low, revealing a close coupling between fermentation and sulfate reduction. Above the $T_{\text {crit }}$ the concentrations increase sharply.

Below the $\boldsymbol{T}_{\text {crit }}$, the $\mathrm{H}_{2}$ concentrations change in accordance to thermodynamic predictions for sulfate reduction control (Hoehler et al., 1998). The VFA concentrations, which do not appear to be thermodynamically controlled, remain at a constant low level. The lack of a concentration change with time shows that fermentation and terminal oxidation respond similarly fast to changing temperatures. Thus, the sulfate reducers have the capacity to respond immediately to the increased fermentation with increasing temperature, indicating that they remain substrate limited. Thus, a potentially faster response by the sulfate reducers would be masked by substrate limitation for the sulfate reducers. 
Comparison of the incubation with (Station $\mathrm{J}$ and WW) and without (Station BC and NHS) substrate addition shows that the optimum temperature for sulfate reduction is not controlled by the VFA concentration, indicating that the optimum temperature of fermentation and sulfate reduction are similar. Radiotracer experiments with sediments from several stations in Svalbard showed no difference in the short-term temperature optimum of sulfate reduction with and without substrate additions (Sagemann et al., 1998). As shown in other experiments, sediment mixing, slurrying or depletion of the dominant electron acceptor breaks the close coupling between fermentation and terminal oxidation. This results in a transient sharp increase in the concentrations of fermentation products that only slowly return to the original steady-state concentrations (Finke, 1999; Hoehler et al., 1999; Arnosti et al., 2005; Finke et al., 2007a,b). This effect has not been sufficiently addressed in previous experiments with sediment suspensions.

Interestingly, the coupling is robust, following a temperature change over a temperature range that widely exceeds the ecological temperatures, especially for the permanently cold sediment. At the temperate site, the maximum summer temperatures at the sediment surface are much closer to the $T_{\text {crit }}$ than the in situ temperature of the permanently cold sediment. The close coupling indicates that the metabolic capacity of the sulfate reducers significantly exceeds fermentation over this broad temperature range.

In the sediment from the permanently cold Station BC, the $\mathrm{H}_{2}$ concentrations reveal a freeenergy yield of $-35 \mathrm{~kJ} \mathrm{~mol}^{-1} \mathrm{~K}^{-1}$ for hydrogenotrophic sulfate reduction. This is considerably higher than the literature values of $-20 \mathrm{~kJ} \mathrm{~mol}^{-1} \mathrm{~K}^{-1}$ reported for temperate sites (Lovley and Goodwin, 1988; Hoehler et al., 1998), but is consistent with bag incubations (Arnosti et al., 2005) and whole core $\mathrm{H}_{2}$ measurements in sediments (Finke, 2003) from Svalbard showing similar $\mathrm{H}_{2}$ concentrations. Whether this increased energy demand is typical for permanently cold sites or just for Svalbard sediments investigated here remains to be tested. The measured $\mathrm{H}_{2}$ concentrations fall parallel to the theoretical curve over a broad temperature range, revealing a thermodynamic control.

Above the $\boldsymbol{T}_{\text {crit }}, \mathrm{H}_{2}$ and VFA show a strong concentration increase. The increase shows that the fermenters have a higher temperature tolerance than the sulfate reducers. $\mathrm{H}_{2}$ and VFA behave differently with incubation time above the $T_{\text {crit }}$.

Hydrogen concentrations show a transient increase with two distinct concentration levels (Figure 9). In the sediment from the permanently cold site, the highest concentrations measured after 4 days of incubation (Figure 9a) indicate that hydrogenotrophic acetogens control the $\mathrm{H}_{2}$ concentrations (according to Equations (5) and (8)). After 29 days
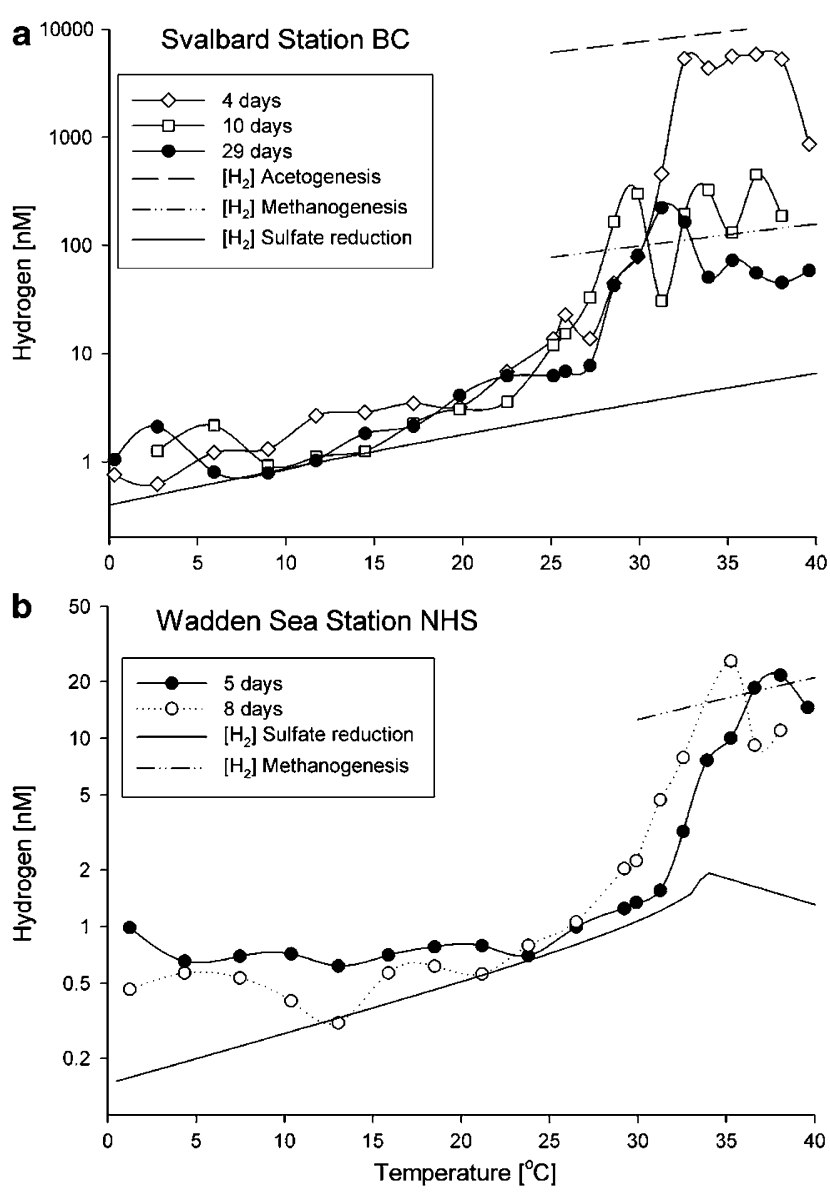

Figure 9 Hydrogen concentrations in sediment from (a) the permanently cold Svalbard Station BC and (b) the temperate Wadden Sea Station NHS, as shown in Figures 3 and 4. Theoretical $\mathrm{H}_{2}$ concentrations for acetogenesis, methanogenesis and sulfate reduction were calculated based on thermodynamic considerations (see text for details). Notice the logarithmic scale for hydrogen.

of incubation, the concentrations seem to be controlled by hydrogenotrophic methanogenesis (according to Equations (4) and (7)). Thus, the acetogenic bacteria apparently respond faster to the increased hydrogen concentrations, but are gradually outcompeted by the methanogens. A similar transient increase in $\mathrm{H}_{2}$ under initial acetogenic control and then methanogenic control has been found in Cape Lookout Bight sediments after sulfate depletion (Hoehler et al., 1999). In the sediments from the temperate site, the concentrations at the end of the experiment after 5 and 8 days indicate control by hydrogenotrophic methanogenesis. Even though methane production has not been determined in these experiments, subsequent incubation of Station BC sediment at $35^{\circ} \mathrm{C}$ showed a steady increase of headspace methane concentration over 30 days of incubation (data not shown). Sediment from the Wadden sea is known to produce methane upon sulfate depletion (Finke et al., 2007a) or at temperatures above $30^{\circ} \mathrm{C}$ (Heuer et al., in prep.). Both acetogens and hydrogenotrophic methanogens must be present in these 
sediments, which do not undergo sulfate depletion. These organisms are ready to consume hydrogen as soon as its concentration exceeds their thermodynamic threshold. Obviously, their upper temperature limit is higher than that of the sulfate reducers.

In contrast to the sediment from Svalbard Station BC, $\mathrm{H}_{2}$ concentrations in NHS sediment deviated from the theoretical curve also at temperatures below $13{ }^{\circ} \mathrm{C}$, where the $\mathrm{H}_{2}$ concentrations stayed constant down to $2{ }^{\circ} \mathrm{C}$ (Figure 4). Constant concentrations with time indicate, that here the change is not due to a shift in degradation pathways but suggest an increased energy demand for hydrogenotrophic sulfate reducers. At the lowest temperature tested, the energy gain for sulfate reduction is the same as that found in the samples from the permanently cold site, supporting this hypothesis. Conrad and Wetter (1990) reported upper and lower critical temperature for methanogenic archaea and acetogenic bacteria with respect to efficient $\mathrm{H}_{2}$ uptake. At temperature extremes beyond the upper and lower critical temperatures, the microorganisms are not able to efficiently remove $\mathrm{H}_{2}$ from media, thus, resulting in elevated concentrations.

Volatile fatty acid also accumulated at temperatures above the $T_{\text {crit }}$. Acetate increased the fastest and to the highest concentrations in both sediments. At very high temperatures and after the second measurement, the concentrations of acetate did not increase much further. This can be due to a shift of the fermentation pathway at high end-product concentrations towards longer chain fatty acids (Schink, 1988) or a new kinetic equilibrium between fermenting and terminal oxidizing microorganisms. The concentrations of the VFA with the longer carbon chains increase throughout the incubation with highest rates at the higher temperatures. With increasing chain length, the VFA concentrations started increasing later, supporting the idea that a shift in the fermentation pathway towards longer VFA is the reason for the much lower acetate accumulation rate after a rapid initial increase. Alternatively, VFA might show only a transient increase, like that in $\mathrm{H}_{2}$ concentrations, on a much longer time frame due to a slower turnover. Hoehler et al. (1999) found the response in acetate concentration after sulfate depletion in temperate coastal sediment to be much slower than that of $\mathrm{H}_{2}$. Incubation of temperate sediments at elevated temperatures showed a slight increase of acetate after 30-50 days in temperate sediment incubated at $30{ }^{\circ} \mathrm{C}$ but no elevated acetate concentrations after 18 months of incubation between 0 and $50{ }^{\circ} \mathrm{C}$ (Parkes et al., 2007).

In the NHS incubations, the $T_{\text {crit }}$ was much lower at the last sampling point compared to the earlier measurements (Figure 6). Extrapolating the sulfate concentrations from the 6-day sampling (Figure 2b) indicate sulfate depletion towards the end of the incubation. Thus, it is very likely that sulfate depletion and a shift in terminal electron accepting process rather than temperature effects are responsible for the increase in VFA concentrations and thus a lowering of $T_{\text {crit }}$.

\section{Fermentation rates}

The overall fermentation rate in complex sedimentary systems can be estimated from the production of the fermentation products. Assuming that acetate is the most important intermediate, a fermentation rate can be estimated based on the change in acetate concentration and the terminal oxidation rate by sulfate reduction (Wellsbury et al., 1997). In both sediments studied, the acetate production closely followed the SRR curve throughout most of the investigated temperatures (Figure 10), showing the same $T_{\text {opt }}$ for fermentation and sulfate reduction in the permanently cold sediment but slightly higher $T_{\text {opt }}$ for fermentation compared to sulfate redution in the temperate sediment.

In the permanently cold sediment, the fermentation rate increased above $27^{\circ} \mathrm{C}$ and showed a second maximum at $30^{\circ} \mathrm{C}$, the temperature of the highest acetate concentrations. This indicates that the permanently cold sediment hosts two groups of
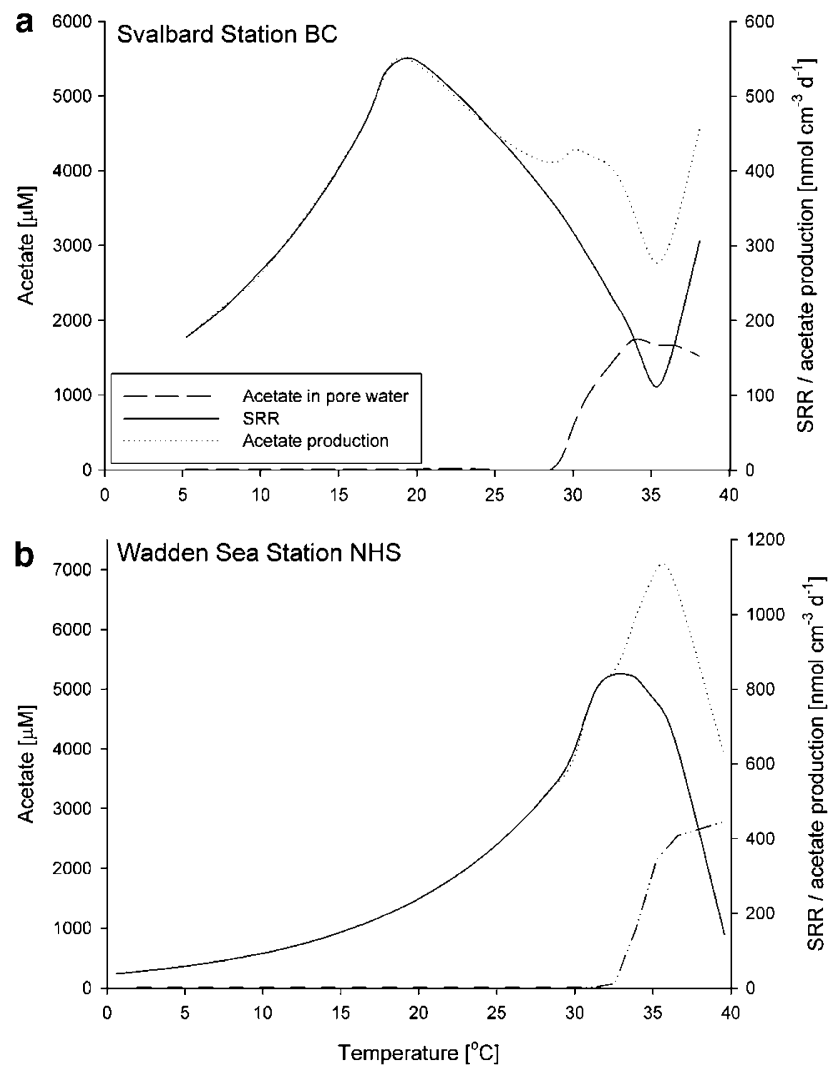

Figure 10 Acetate production in the samples from (a) the permanently cold Svalbard Station BC and (b) the temperate Wadden Sea Station NHS. The acetate production was calculated from the measured acetate concentrations (Figures $6 \mathrm{~b}$ and $8 \mathrm{~b}$ ) and the sulfate reduction rate (SRR) (Figures $1 \mathrm{~b}$ and $2 \mathrm{~b}$ ), based on the simplified assumption that acetate is the only substrate for sulfate reduction. 
fermenting organisms with distinctly different $T_{\text {opt }}$ of 19 and $30^{\circ} \mathrm{C}$, corresponding to a psychrophilic and a mesophilic population. In contrast, the sediment from the temperate site showed only a mesophilic $T_{\text {opt }}$ of $34{ }^{\circ} \mathrm{C}$ for fermentation within the tested temperature window. The drop in calculated acetate production above $30^{\circ} \mathrm{C}$ in the permanently cold sediment might be due to a shift in fermentation products rather than a decrease in fermentation rate. Thus, the actual $T_{\text {opt }}$ of the second group of fermenters might be even higher than $30^{\circ} \mathrm{C}$.

\section{Conclusions}

Temperature is a key environmental factor influencing microbial processes in aquatic systems. SRRs as well as calculated fermentation rates showed a strong dependence on incubation temperature. Concentrations of the important intermediates between these two processes, VFA and $\mathrm{H}_{2}$, however, remain low over a broad temperature range, revealing a close coupling between sulfate reduction and fermentation.

The sediment from the permanently cold station shows a constant close coupling and active sulfate reduction down to the lowest temperatures tested. At the upper temperature end, which is far above the in situ temperatures, the sulfate reduction decreases with time, shifting the optimum temperature towards lower values. This reveals a strong adaption by the fermentative and sulfate-reducing populations to the low in situ temperatures.

The sediment from the temperate site showed increasing energy demand for hydrogenotrophic sulfate reducers with decreasing temperatures below $13{ }^{\circ} \mathrm{C}$, resulting in increased $\mathrm{H}_{2}$ concentrations. At the upper temperature end, which is close to the highest in situ temperature, optimum temperature for sulfate reduction and critical temperature for VFA and $\mathrm{H}_{2}$ consumption vary only by a few degrees. The populations in the temperate sediments show a stronger adaptation towards the higher temperatures, with potentially higher rates, than towards the low winter temperatures.

High intermediate concentrations above the critical temperatures show that fermentative bacteria tolerated higher temperatures than sulfate reducers. $\mathrm{H}_{2}$ concentrations at high temperatures show that acetogenic and methanogenic microorganisms, tolerating higher temperatures, are present in these sediments that never undergo sulfate depletion in situ.

The presented experiments offer insight in the effect of temperature changes on the coupling of sulfate reduction and fermentation. Both sediments show a strong coupling over a temperature range, that strongly exceeds environmentally relevant temperatures. The physiological overcapacity of the sulfate reducers to degrade the fermentation products is not affected by the temperature change.
This is counter to observations made with other manipulations, such as mixing and change of electron donor, which both lead to temporary increase in intermediate concentration. Only beyond a critical temperature for the sulfate reducers, this coupling is broken, resulting in increased intermediate concentrations as also seen after mixing and change of electron donor. Investigating the response of fermentation and sulfate reduction to temperature changes deepen our understanding of the coupling of the microbial food chain in marine sediments.

\section{Acknowledgements}

We thank Jens Harder and Tori M Hoehler for stimulating discussions. We thank Stig Henningsen for the support on board MS FARM, and the Koldewey Station for support in Ny lesund, Svalbard. This study was supported by the German Max Planck Society.

\section{References}

Albert DB, Martens CS. (1997). Determination of lowmolecular-weight organic acid concentrations in seawater and pore-water samples via HPLC. Mar Chem 56: $27-37$.

Arnosti C, Finke N, Larsen O, Ghobrial S. (2005). Anoxic carbon degradation in Arctic sediments: microbial transformations of complex substrates. Geochim Cosmochim Acta 69: 2309-2320.

Arnosti C, Jørgensen BB. (2003). High activity and low temperature optima of extracellular enzymes in Arctic sediments: implications for carbon cycling by heterotrophic microbial communities. Mar Ecol Prog Ser 249: 15-24.

Arnosti C, Jørgensen BB, Sageman J, Thamdrup B. (1998). Temperature dependence of microbial degradation of organic matter in marine sediments: polysaccharide hydrolysis, oxygen consumption, and sulfate reduction. Mar Ecol Prog Ser 165: 59-70.

Böttcher ME, Hespenheide B, Llobet-Brossa E, Beardsley C, Larsen O, Schramm A et al. (2000). The biogeochemistry, stable isotope geochemistry, and microbial community structure of a temperate intertidal mudflat: an integrated study. Cont Shelf Res 20: 17491769.

Capone DG, Kiene RS. (1988). Comparison of microbial dynamics in marine and freshwater sediments: contrasts in anaerobic carbon catabolism. Limn Oceanogr 33: $725-749$.

Christensen D, Blackburn TH. (1982). Turnover of ${ }^{14} \mathrm{C}$ labelled acetate in marine sediments. Mar Biol 71: 113-119.

Christian RR, Wiebe WJ. (1974). Effects of temperature upon reproduction and respiration of a marine obligate psychrophile. Can J Microbiol 20: 1341-1345.

Conrad R, Wetter B. (1990). Influence of temperature on energetics of hydrogen metabolism in homoacetogenic, methanogenic, and other anaerobic-bacteria. Arch Microbiol 155: 94-98. 
Crill PM, Martens CS. (1987). Biogeochemical cycling in an organic-rich coastal marine basin .6. temporal and spatial variations in sulfate reduction rates. Geochim Cosmochim Acta 51: 1175-1186.

Croizer TE, Yamamoto S. (1974). Solubility of hydrogen in water, seawater, and $\mathrm{NaCl}$ solutions. J Chem Eng Data 19: $242-244$.

Damgaard LR, Hanselmann K. (2002). THERMODYN ${ }^{\circ}$ : a simple excel spreadsheet for the calculation of free reaction energies. In: A Product of the Woods Hole Microbial Diversity Courses, 1996-1999. http:// www.microeco.unizh.ch/therm/thermodyn.html.

Elsgaard L, Isaksen MF, Jørgensen BB, Alayse AM, Jannasch HW. (1994). Microbial sulfate reduction in deep-sea sediments at the Guaymas basin-hydrothermal vent area-influence of temperature and substrates. Geochim Cosmochim Acta 58: 3335-3343.

Ferdelman TG, Lee C, Pantoja S, Harder J, Bebout BM, Fossing H. (1997). Sulfate reduction and methanogenesis in Thioploca-dominated sediment off the coast of Chile. Geochim Cosmochim Acta 61: 3065-3079.

Finke N. (1999). Die relative Bedeutung kurzkettiger Carbonsäuren für sulfatreduzierende Bakterien in polaren Schelfsedimenten und der Einfluss von erhöhter Temperatur. MSc Thesis, University of Bremen, Bremen.

Finke N. (2003) The role of volatile fatty acids and hydrogen in the degradation of organic matter in marine sediments. PhD thesis, University of Bremen, Bremen.

Finke N, Hoehler TM, Jørgensen BB. (2007a). Hydrogen 'leakage' during methanogenesis from methanol and methylamine: implications for anaerobic carbon degradation pathways in aquatic sediments. Envrion Microbiol 9: 1060-1071.

Finke N, Vandieken V, Jørgensen BB. (2007b). Acetate, lactate, propionate, and isobutyrate as electron donors for iron and sulfate reduction in Arctic marine sediments, Svalbard. FEMS Microbiol Ecol 59: 10-22.

Fossing H, Jørgensen BB. (1989). Measurement of bacterial sulfate reduction in sediments-evaluation of a singlestep chromium reduction method. Biogeochemistry 8: 205-222.

Hansen JW, Thamdrup B, Jørgensen BB. (2000). Anoxic incubation of sediment in gas-tight plastic bags: a method for biogeochemical process studies. Mar Ecol Prog Ser 208: 273-282.

Harder W, Veldkamp H. (1967). A continous culture study of an obligately psychrophilic pseudomonas species. Arch Mikrobiol 59: 123-130.

Hoehler TM. (2004). Biological energy requirements as quantitative boundary conditions for life in the subsurface. Geobiology 2: 205-215.

Hoehler TM, Albert DB, Alperin MJ, Martens CS. (1999). Acetogenesis from $\mathrm{CO}_{2}$ in an anoxic marine sediment. Limnol Oceanogr 44: 662-667.

Hoehler TM, Alperin MJ, Albert DB, Martens CS. (1994). Field and laboratory studies of methane oxidation in an anoxic marine sediment-evidence for a methanogen-sulfate reducer consortium. Glob Biogeochem Cycle 8: 451-463.

Hoehler TM, Alperin MJ, Albert DB, Martens CS. (1998). Thermodynamic control on hydrogen concentrations in anoxic sediments. Geochim Cosmochim Acta 62: 1745-1756.

Isaksen MF, Bak F, Jørgensen BB. (1994). Thermophilic sulfate-reducing bacteria in cold marine sediment. FEMS Microbiol Ecol 14: 1-8.
Isaksen MF, Jørgensen BB. (1996). Adaptation of psychrophilic and psychrotrophic sulfate-reducing bacteria to permanently cold marine environments. Appl Environ Microbiol 62: 408-414.

Jørgensen BB. (1978). A comparison of methods for the quantification of bacterial sulfate reduction in coastal marine sediments: I. Measurement with radiotracer techniques. Geomicrobiol J 1: 11-27.

Jørgensen BB. (1982). Mineralization of organic-matter in the sea bed-the role of sulfate reduction. Nature 296: $643-645$.

Jørgensen BB, Sørensen J. (1985). Seasonal cycles of $\mathrm{O}_{2}$, $\mathrm{NO}_{3}^{-}$and $\mathrm{SO}_{4}^{2-}$ reduction in estuarine sediments: the significance of an NO-3 reduction maximum in spring. Mar Ecol Prog Ser 24: 65-74.

Kanneworff E, Nicolaisen W. (1983). A simple, handoperated quantitative bottom sampler. Ophelia 22: 253-255.

Knoblauch C, Jørgensen BB. (1999). Effect of temperature on sulphate reduction, growth rate and growth yield in five psychrophilic sulphate-reducing bacteria from Arctic sediments. Environ Microbiol 1: 457-467.

Lovley DR, Goodwin S. (1988). Hydrogen concentrations as an indicator of the predominant terminal electronaccepting reactions in aquatic sediments. Geochim Cosmochim Acta 52: 2993-3003.

Miller JF, Shah NN, Nelson CM, Ludlow JM, Clark DS. (1988). Pressure and temperature effects on growth and methane production of the extreme thermophile Methanococcus jannaschii. Appl Environ Microbiol 54: 3039-3042.

Nedwell DB. (1999). Effect of low temperature on microbial growth: lowered affinity for substrates limits growth at low temperature. FEMS Microbiol Ecol 30: 101-111.

Nickel M. (2006). Mineralization pathways and thermophilic sulfate reduction in Arctic sediments, Svalbard. $\mathrm{PhD}$ thesis, University of Bremen, Bremen, p 95.

Parkes RJ, Wellsbury P, Meather ID, Cobb SJ, Cragg BA, Hornibrook ERC et al. (2007). Temperature activation of organic matter and minerals during burial has the potential to sustain the deep biosphere over geological timescales. Org Geochem 38: 845-852.

Pomeroy LR, Wiebe WJ. (2001). Temperature and substrates as interactive limiting factors for marine heterotrophic bacteria. Aquat Microb Ecol 23: 187-204.

Sagemann J, Jørgensen BB, Greef O. (1998). Temperature dependence and rates of sulfate reduction in cold sediments of Svalbard, Arctic Ocean. Geomicrobiol J 15: $85-100$.

Schink B. (1988). Principles and limits of anaerobic degradation: environmental and technological aspects. In: Zehnder AJB (ed). Biology of Anaerobic Microorganisms. John Wiley \& Sons, New York. pp 771-846.

Schink B. (1997). Energetics of syntrophic cooperation in methanogenic degradation. Microbiol Mol Biol Rev 61: 262-280.

Thamdrup B, Fleischer S. (1998). Temperature dependence of oxygen respiration, nitrogen mineralization, and nitrification in Arctic sediments. Aquat Microb Ecol 15: 191-199.

Thamdrup B, Hansen JW, Jørgensen BB. (1998). Temperature dependence of aerobic respiration in a coastal sediment. FEMS Microbiol Ecol 25: 189-200. 
Wellsbury P, Goodman K, Barth T, Cragg BA, Barnes SP, Parkes RJ. (1997). Deep marine biosphere fuelled by increasing organic matter availability during burial and heating. Nature 388: 573-576.

Wellsbury P, Parkes RJ. (1995). Acetate bioavailability and turnover in an estuarine sediment. FEMS Microbiol Ecol 17: 85-94.

Westermann P. (1992). The effect of temperature on the metabolism of hydrogen and butyrate in a temperate swamp ecosystem. Suo 43: 289-292.
Westrich JT, Berner RA. (1988). The effect of temperature on rates of sulfate reduction in marine sediments. Geomicrobiol J 6: 99-117.

Wiebe WJ, Sheldon WM, Pomeroy LR. (1993). Evidence for an enhanced substrate requirement by marine mesophilic bacterial isolates at minimal growth temperatures. Microb Ecol 25: 151-159.

Wu HG, Scranton MI. (1994). Cycling of some lowmolecular-weight volatile fatty-acids in a permanently anoxic estuarine basin. Mar Chem 47: 97-113. 